\title{
Editor's Message: University of Kansas (USA) plagiarism allegations regarding two Hydrogeology Journal articles by Dr. Marios Sophocleous
}

\section{Clifford I. Voss}

In late February 2013, the Kansas Geological Survey (KGS), a research and service division of the University of Kansas (KU), found that a number of papers written by a then staff member, Dr. Marios Sophocleous (retired from KGS in June 2013), appeared to have been plagiarized from earlier work. KU explained to Hydrogeology Journal that, following multi-stage investigations, which included opportunities for Dr. Sophocleous to explain his actions, KU concluded that Dr. Sophocleous had committed scholarly misconduct. KU then publicly censured him (University of Kansas 2013).

Two of the seven articles cited in the censure statement appeared in Hydrogeology Journal $(H J)$ and KU has requested of publisher Springer and the $H J$ executive editor (EE) that both be retracted. KU provided a detailed analysis of each paper, indicating which passages were plagiarized and the source of the plagiarized material; these analyses are available from KGS upon request.

The two articles are:

Sophocleous M (2002) Interactions between groundwater and surface water: the state of the science, Hydrogeology Journal, vol. 10, no. 1, pp. 52-67.

http://link.springer.com/article/10.1007/s10040-001-0170-8

Sophocleous M (2010) Review: groundwater management practices, challenges, and innovations in the High Plains aquifer, USA - lessons and recommended actions, Hydrogeology Journal, vol. 18, no. 3, pp. 559-575.

http:/link.springer.com/article/10.1007/s10040-009-0540-1

Published online: 20 December 2014

(C) Springer-Verlag Berlin Heidelberg (outside the USA) 2014

C. Voss is the Executive Editor of Hydrogeology Journal

This comment refers to the article available at:

http://dx.doi.org/10.1007/s10040-009-0540-1

http://dx.doi.org/10.1007/s10040-001-0170-8

C. I. Voss (®)

US Geological Survey,

345 Middlefield Road, MS 496, Menlo Park, CA 94025, USA

e-mail: cvoss@usgs.gov
The EE and publisher, Springer, did independent reviews of the papers and agree with KU that a large portion of the text was copied verbatim from previous articles written by other authors. The copied passages all lacked quotation marks to indicate that they were directly quoted from previous works.

The EE's assessment is as follows. In most cases, the reference from which the material was copied verbatim is given close by in the text by Sophocleous. Thus, Sophocleous did not claim that the copied ideas were his own; however, Sophocleous neglected to indicate that he had not composed these passages by including quotation marks around copied text. It is clear that review articles normally consist of information compiled from previous works, but text copied verbatim must be enclosed in quotation marks. Thus, the copied unquoted text must be strictly considered as plagiarism, but Sophocleous' referencing of most copied passages indicates that he was giving credit to the previous authors from which he copied, and not hiding the fact that the material was not his own. In a positive view, his error might be considered to be a technical one, in which he neglected to use quotation marks; however, the EE and Springer agree with KU that this style of presenting information from previous works, even in review articles, is unacceptable.

KU has stated that it views these papers as compilations of plagiarized material and has requested they be withdrawn to demonstrate to the hydrological community that such practices cannot be tolerated. One response to the KU retraction request that was considered by the EE was to republish the two articles with all necessary quotation marks in place; however, this would appear peculiar as a large portion of the text in each article would be within quotes. This makes it clear that reviewers would have rejected a manuscript composed of largely quoted material.

In deciding how to respond to the retraction request, the $\mathrm{EE}$ has also considered the value of these two articles to the scientific readership. Both articles are reviews of their subject matter, not presentations of new scientific results. These $H J$ articles are highly cited and indeed, one is among the most highly cited 
of all time in $H J$. Thus, both articles were and are still of clear value to the scientific community. Therefore, the EE has concluded that retraction would be a disservice to the community.

$\mathrm{KU}$ disagrees with the conclusion of the $\mathrm{EE}$ and continues to assert that both papers should be retracted. However, in the interest of bringing the matter to a close, $\mathrm{KU}$ has agreed to accept publication of this Editor's
Message in place of retraction, given that a link to this is attached to both papers in the Springer online archives.

\section{References}

University of Kansas (2013) Public censure. news.ku.edu/2013/12/ 11/public-censure. Accessed November 2014 